\title{
Continuity of care in general practice: effect on patient satisfaction
}

\author{
Per Hjortdahl, Even Lærum
}

\begin{abstract}
Objective-To evaluate the influence of continuity of care on patient satisfaction with consultations.

Design-Direct and episodic specific evaluation of patient satisfaction with recent consultation.

Setting and subjects $-A$ representative sample of 3918 Norwegian primary care patients were asked to evaluate their consultations by filling in a questionnaire. The response rate was $78 \%$.

Main outcome measures-The patient's overall satisfaction with the consultation was rated on a six point scale. Continuity of care was recorded as the duration and intensity of the present patient-doctor relationship and as patients' perception of the present doctor being their personal doctor or not.

Results - The multivariate analysis indicated that an overall personal patient-doctor relationship increased the odds of the patient being satisfied with the consultation sevenfold $(95 \%$ confidence interval 4.9 to 9.9) as compared with consultations where no such relationships existed. The duration of the patient-doctor relationship had a weak but significant association with patient satisfaction, while the intensity of contacts showed no such association.

Conclusion-Personal, continuous care is linked with patient satisfaction. If patient satisfaction is accepted as an integral part of quality health care, reinforcing personal care may be one way of increasing this quality.
\end{abstract}

\section{Introduction}

Patient satisfaction is an important dimension in the evaluation of quality of health care. Evidence has accumulated that care which is less satisfactory to the patient is associated with non-compliance with treatment and return appointments and a poor understanding and retention of medical information. ' Patient satisfaction also reflects technical competence of doctors, ${ }^{2}$ and evidence is emerging that satisfaction may be directly related to improvement in the health status of patients.

Satisfaction represents complex relations between the patient's perceived needs, expectations, and experience of care. Studies have suggested a number of dimensions of satisfaction and Ware and Snyder have identified four independent factors, of which continuity of care is one that explains most of the variation in satisfaction. ${ }^{4}$

Continuity has commonly been viewed quantitatively as a succession of visits to the same provider. ${ }^{5}$ Banahan and Banahan, however, described it mainly as a qualitative phenomenon that may occur between patient and physician. ${ }^{6}$ In their view, continuity of care can best be characterised as a mutual attitudinal contract in which patients perceive a dependency on the physician for some or all of their primary health care needs and the physician accepts a responsibility for these needs.

Provider continuity may be seen both as an antecedent to patient satisfaction and as a behavioural consequence of satisfaction with a previous encounter. With the importance placed on provider continuity in the "cycle of care" and patient satisfaction" it is surprising that, as shown in a recent meta-analysis of the literature on satisfaction, continuity was evaluated in only 10 of 221 studies. $^{8}$ Most of these were done in the United States and limited to primary care physicians in postgraduate training in hospitals or outpatient clinics or to special patient populations. Their general value may accordingly be limited.

Personal and continuous care has long been held to be the cornerstone of primary care. In the face of major structural changes in the primary health care delivery system this cornerstone may erode. ${ }^{9}$ As part of a larger assessment of the patient-doctor relationship ${ }^{10}$ the present study was undertaken to evaluate the influence of continuity of care on patient satisfaction in an unselected population of patients in primary care. Our hypothesis is that continuous, personal doctoring increases patient satisfaction.

\section{Subjects and methods}

The study took place during the spring of 1987. A random sample of 133 Norwegian general practitioners each agreed to record 30 consecutive surgery consultations, scheduled and unscheduled, with patients of all ages. The physician recorded the age and sex of the patient, the main reason for the encounter, and the duration and intensity of the doctor-patient relationship. At the end of each consultation the doctor handed the patient a sealed envelope, asking the patient to take it home, read it, and follow the included instructions. In consultations with children the accompanying adults were asked to complete the questionnaire.

The envelope contained an explanation of the study, an assurance that their physician would not see the answer, and a two page, self explanatory questionnaire pertaining to the present patient-doctor relationship and satisfaction with the consultation they had just finished. A stamped, self addressed envelope was included for return of the questionnaire directly to the department of general practice in Oslo. The questionnaire was anonymous and no effort was made to reach non-responders. Each questionnaire and doctor's recording were given similar numbers, and basic information about the non-responders could be obtained from the doctors' recordings. The participating physicians were not informed about either the content of the envelope they gave to the patients or the nature of the questionnaire.

The patient's perception of continuity of care was recorded on two dimensions. Longitudinal care was noted as the duration of the relationship (time since
Correspondence to: Dr Hjortdahl.

BMF 1992;304:1287-90 
first encounter with this specific doctor) and intensity (the number of encounters with the doctor during the previous 12 months). In Norway, where patients are free to change primary care physicians at will, the relationship that may develop is usually unspoken and frequently unconscious. "Continuity of care" is an expression not well understood by the layman. During the pilot phase of the project it was found that the common phrase "having a personal doctor" best captured the qualitative dimension of continuity of care. The following response alternatives were given: today's doctor was not my personal doctor; or, today's doctor was the personal doctor for some, for most, or for all my health problems.

Patient satisfaction was recorded as the answers to 10 specific questions pertaining to the doctor's communicative skills and technical proficiency, and with the answer to one general question relating to the overall satisfaction with the consultation. Possible responses ranged through six steps: very great, great, fair, somewhat, slight, and no satisfaction, with a separate category for uncertain. As each of the 10 specific responses correlated to a large degree with the overall response (coefficients between 0.74 and 0.83 ) this global evaluation was used in the final analysis. Owing to the skewness of answers the respondents were dichotomised into "very satisfied," including those who had indicated very great or great satisfaction, and "less satisfied" for the remainder.

The main reason for the encounter as noted by the physician was coded by the authors in accordance with the new International Classification of Primary Care (ICPC). ${ }^{1}$ The doctor's availability to patients was recorded as the average hours per week in clinical practice.

Multiple logistic regression ${ }^{12}$ was used to evaluate the relative importance of continuity of care for patient satisfaction, and factors related to patient, doctor, and reason for encounter were controlled for. The doctor's age, stability, and availability were continuous variables, and the others were categorical. This had the effect that the odds ratios for the continuous variables appeared very close to $1 \cdot 0$, as they applied to a single unit of the variable. Fifteen patients were left out of this analysis owing to uncertain answers or incomplete data sets.

As a test of robustness of the dichotomised analysis the 10 specific satisfaction responses of each patient were treated as a single additive scale. A multiple linear regression analysis was done with the same independent variables and the new, continuous values of satisfaction

TABLE I-Influence of the doctor-patient relationship on patient satisfaction with the consultation. Results are numbers (row percentages)

\begin{tabular}{|c|c|c|c|c|}
\hline & \multicolumn{3}{|c|}{ Overall satisfaction with present consultation } & \multirow[b]{2}{*}{ Total } \\
\hline & Very great/great & Fair/somewhat & $\begin{array}{l}\text { Slight/none } \\
\text { at all }\end{array}$ & \\
\hline \multicolumn{5}{|l|}{ Today's doctor was: } \\
\hline Not my personal doctor & $230(64)$ & $108(30)$ & $19(5)$ & $357(99)$ \\
\hline Some of my health problems & $142(68)$ & $54(26)$ & $12(6)$ & $208(100)$ \\
\hline Most of my health problems & $644(78)$ & $170(21)$ & $10(1)$ & $824(100)$ \\
\hline All my health problems & $1495(90)$ & $146(9)$ & $11(1)$ & $1652(100)$ \\
\hline Total & $2511(82)$ & $478(16)$ & $52(2)$ & $3041(100)$ \\
\hline \multicolumn{5}{|c|}{ Duration of doctor-patient relationship (time since first encounter): } \\
\hline First contact today & $185(77)$ & $46(19)$ & $10(4)$ & $241(100)$ \\
\hline$<3$ Months & $135(75)$ & $45(25)$ & 0 & $180(100)$ \\
\hline 3-12 Months & $287(78)$ & $74(20)$ & $6(2)$ & $367(100)$ \\
\hline $1-5$ Years & $1008(83)$ & $191(16)$ & $19(2)$ & $1218(101)$ \\
\hline$>5$ Years & $893(87)$ & $122(12)$ & $17(2)$ & $1032(101)$ \\
\hline Total & $2508(82)$ & $478(16)$ & $52(2)$ & $3038(100)$ \\
\hline \multicolumn{5}{|c|}{ Intensity of doctor-patient relationship (No of encounters in last 12 months): } \\
\hline Present encounter only & $378(78)$ & $88(18)$ & $16(3)$ & $482(99)$ \\
\hline $2-3$ & $788(80)$ & $177(18)$ & $15(2)$ & $980(100)$ \\
\hline 45 & $431(86)$ & $63(13)$ & $9(2)$ & $503(101)$ \\
\hline $6-10$ & $608(85)$ & $101(14)$ & $8(1)$ & $717(100)$ \\
\hline$\geqslant 11$ & $299(85)$ & $48(14)$ & $5(1)$ & $352(100)$ \\
\hline Total & $2504(82)$ & $477(16)$ & $53(2)$ & $3034(100)$ \\
\hline
\end{tabular}

as the dependent variable. The numerical results were somewhat different, but the significant findings were the same with both methods.

\section{Results}

The 133 participating physicians recorded 3918 out of a possible 3990 consultations. The patients' age, sex, and morbidity patterns were closely compatible with those in a previous representative survey.$^{13}$ In all, 3044 $(78 \%)$ of the questionnaires were returned. No significant differences were observed in age, sex, or morbidity pattern between responders and non-responders. There was, however, a somewhat higher proportion of new patients among the non-responders $(15 \% v 9 \%$, $\mathrm{p}<0.001$ ), and a greater usage of emergency and unscheduled appointments among non-responders $(26 \%$ v $21 \%, p<0.004)$.

The mean age of the respondents was 39 (range 0-98) years and among the participating physicians 38 (30-70) years. The doctors had been in general practice in the same geographical area for an average of seven $(0-40)$ years. They did a mean of $27(12-45)$ hours of clinical work a week.

As shown in table I, 1652 (54\%) of all patients considered the present doctor to be their regular doctor for all their primary health care needs, 1032 (34\%) named him or her as their regular doctor for some of their health needs, and $357(12 \%)$ did not feel any personal relationship had been established with the present doctor. A total of $241(8 \%)$ of the patients met a new doctor, while 1032 (34\%) had known him or her for more than five years. Slightly less than half (1462; $48 \%$ ) of the patients had three or fewer consultations, while $352(12 \%)$ had 11 or more with the present doctor during the previous 12 months.

Table II shows the multivariate relation between continuity of care and satisfaction with the consultation, controlled for patient and doctor related factors and factors related to the consultation and illness. An overall personal patient-doctor relationship increased the odds of the patient being satisfied with the consultation sevenfold as compared with consultations where no such relationships existed. When the doctor was considered responsible only for some of the needs the odds of being satisfied increased by $50 \%$ as compared with new relationships, and it was two and a half times as great if the doctor was considered responsible for most of the patient's primary health care needs. The duration of the patient-doctor relationship in itself showed a weak but significant association with patient satisfaction, taking as much as five years to develop. The intensity of contacts showed a lesser, not significant association with patient satisfaction.

The present study did not find any significant associations between the age or gender of the patient and satisfaction with the consultation, nor did the doctor's age or gender, or the stability or location of the practice, or the type of partnership seem to influence patient satisfaction (table II). The patient had, however, a significant, $40 \%$ increased chance of being satisfied with consultations with doctors on a fee for service system as compared with consultations with salaried doctors.

There was a significant relation between the doctor's availability, as measured by hours of curative practice a week, and patient satisfaction with the consultation. A doctor spending 40 hours a week at the office with curative work had an $82 \%$ increased chance of having patients satisfied with the consultation as compared with a doctor working only 20 curative hours a week. There was a trend, though not significant, for patients to be less satisfied with unscheduled and emergency appointments as compared with those scheduled, and to be more satisfied with consultations arising from 
TABLE II - Influence of continuity of care on patient satisfaction with consultation, evaluated by multiple logistic regression, controlling for patient, doctor, and consultation related factors. Patient satisfaction with the consultation: $0=$ less satisfied $(n=530) ; 1=$ very satisfied $(n=2499)$

\begin{tabular}{|c|c|c|c|c|}
\hline & No & $\begin{array}{c}\text { Odds ratio }(95 \% \\
\text { confidence interval) }\end{array}$ & $\mathrm{p}$ Value & Estimate (SE) \\
\hline \multirow{2}{*}{\multicolumn{5}{|c|}{ Factors related to continuity of care }} \\
\hline Today's doctor was: & & & & \\
\hline \multicolumn{5}{|l|}{ My personal doctor for: } \\
\hline Some of my health problems & 207 & $1.48(0.99$ to $2 \cdot 19)$ & 0.060 & $0.39(0.20)$ \\
\hline Most of my health problems & 821 & $2.62(1.87$ to 3.64$)$ & 0.001 & $0.96(0 \cdot 17)$ \\
\hline All my health problems & 1644 & $6.95(4.89$ to 9.90$)$ & 0.001 & $1.94(0 \cdot 18)$ \\
\hline \multicolumn{5}{|c|}{ Duration of doctor-patient relationship (time since first encounter): } \\
\hline First contact today & 241 & $1 \cdot 0$ & & \\
\hline$<3$ Months & 179 & $1.03(0.66$ to 1.61$)$ & 0.915 & $0.03(0.23)$ \\
\hline 3-12 Months & 366 & $1.24(0.91$ to 1.71$)$ & $0 \cdot 173$ & $0.22(0 \cdot 16)$ \\
\hline $1-5$ Years & 1215 & $1.32(0.92$ to 1.86$)$ & $0 \cdot 129$ & $0.27(0.18)$ \\
\hline$>5$ Years & 1028 & $1.85(1.07$ to $3 \cdot 19)$ & 0.026 & $0.61(0.28)$ \\
\hline \multicolumn{5}{|c|}{ Intensity of doctor-patient relationship (No of encounters in past 12 months): } \\
\hline Present encounter only & 485 & $1 \cdot 0$ & & \\
\hline $2-3$ & 979 & $1.03(0.71$ to 1.50$)$ & 0.889 & $0 \cdot 03(0 \cdot 19)$ \\
\hline $4-5$ & 502 & $1.10(0.75$ to 1.59$)$ & 0.631 & $0.09(0.19)$ \\
\hline $6-10$ & 715 & $1.20(0.79$ to 1.79$)$ & 0.400 & $0 \cdot 17(0 \cdot 21)$ \\
\hline$\geqslant 11$ & 351 & $1.27(0.83$ to 1.96$)$ & 0.268 & $0 \cdot 24(0.22)$ \\
\hline \multicolumn{5}{|c|}{ Factors related to patient } \\
\hline Age (years): & & & & \\
\hline$\geqslant 15$ & 193 & 1.0 & & \\
\hline $16-69$ & 2266 & $1.08(0.72$ to 1.64$)$ & 0.721 & $0.08(0.21)$ \\
\hline$\geqslant 70$ & 570 & $1.04(0.65$ to 1.67$)$ & 0.879 & $0.04(0.24)$ \\
\hline \multicolumn{5}{|l|}{ Sex: } \\
\hline Female & 2024 & $1 \cdot 0$ & & \\
\hline Male & 1005 & $0.99(0.80$ to 1.23$)$ & 0.937 & $-0.01(0 \cdot 11)$ \\
\hline \multicolumn{5}{|c|}{ Factors related to doctor } \\
\hline Age (years) & & $1.0(0.99$ to 1.03$)$ & 0.727 & $0.01(0.01)$ \\
\hline \multicolumn{5}{|l|}{ Sex: } \\
\hline Female & 835 & $1 \cdot 0$ & & \\
\hline Male & 2194 & $0.92(0.71$ to 1.18$)$ & $0 \cdot 500$ & $-0.09(0.13)$ \\
\hline Stability of doctor in practice (years) & & $0.99(0.97$ to 1.01$)$ & $0 \cdot 334$ & $-0.01(0.01)$ \\
\hline \multicolumn{5}{|l|}{ Location of practice: } \\
\hline Major cities & 450 & 1.0 & & \\
\hline Towns & 1120 & $1.05(0.77$ to 1.44$)$ & 0.749 & $0 \cdot 05(0 \cdot 16)$ \\
\hline Rural area & 1459 & $0.95(0.71$ to 1.28$)$ & 0.731 & $-0.05(0.15)$ \\
\hline \multicolumn{5}{|l|}{ Type of practice: } \\
\hline Solo practitioner & 770 & $1 \cdot 0$ & & \\
\hline Dual partnership & 785 & $1.05(0.77$ to 1.44$)$ & 0.750 & $0.05(0 \cdot 16)$ \\
\hline Group practice & 1474 & $0.95(0.71$ to 1.28$)$ & 0.733 & $-0.05(0.15)$ \\
\hline \multicolumn{5}{|l|}{ Reimbursement: } \\
\hline Set salary & 1099 & 1.0 & & \\
\hline Fee for service & 1930 & $1.38(1.10$ to 1.78$)$ & 0.011 & $0.32(0 \cdot 13)$ \\
\hline \multirow[t]{2}{*}{ Availability (clinical hours a week) } & & $1.03(1.01$ to 1.05$)$ & 0.004 & $0.03(0.01)$ \\
\hline & \multicolumn{4}{|c|}{ Factors related to consultation } \\
\hline Type: & & & & \\
\hline Scheduled & 2395 & $1 \cdot 0$ & & \\
\hline Unscheduled & 341 & $0.91(0.68$ to 1.23$)$ & 0.558 & $-0.09(0 \cdot 15)$ \\
\hline Emergency & 293 & $0.82(0.59$ to 1.14$)$ & 0.235 & $-0 \cdot 20(0 \cdot 17)$ \\
\hline \multicolumn{5}{|l|}{ Type of illness: } \\
\hline Somatic or non-psychosocial & 2755 & $1 \cdot 0$ & & \\
\hline Psychosocial & 274 & $0.54(0.40$ to 0.74$)$ & 0.001 & $-0.61(0 \cdot 16)$ \\
\hline \multicolumn{5}{|l|}{ Duration of problem: } \\
\hline New & 1053 & $1 \cdot 0$ & & \\
\hline Follow up & 698 & $1.15(0.87$ to 1.51$)$ & $0 \cdot 326$ & $0 \cdot 14(0 \cdot 14)$ \\
\hline Chronic & 955 & $1.41(0.95$ to 2.08$)$ & 0.090 & $0.34(0.20)$ \\
\hline Preventive or other & 323 & $1.08(0.82$ to 1.41$)$ & 0.618 & $0.07(0 \cdot 14)$ \\
\hline
\end{tabular}

chronic problems than those arising from new ones. Patients with psychosocial reasons for encounter showed significantly less satisfaction with their consultations than patients with somatic problems.

\section{Discussion}

Previous studies have shown that numerous factors influence patient satisfaction, but most do so in minor ways. ${ }^{14}$ The sevenfold odds ratio shown in the present study is substantial and suggests a close linkage between personal care and patient satisfaction. There may be several explanations for this finding. It may be an artefact of study design. In spite of the high response rate and the representativeness of the sample, the response bias may have influenced the results. As is evident in table II, new patients and patients with unscheduled or emergency appointments were somewhat less satisfied. Other studies have shown that nonresponders tend to be less satisfied. ${ }^{15}$ If this holds true in the present setting, inclusion of the non-responders might have made new patients even less satisfied than shown, inflating the personal care odds ratio even further.
Personal care and satisfaction are related cognitive constructs that may be mixed by the respondents. To reduce the possibility of measuring the same thing the constructs were evaluated through independent questions and on separate pages of the questionnaire. From interviews with respondents in the pilot phase we believe that this source of error did not have a great role.

In this study we used an approach that was both direct and specific to the episode to evaluate patient satisfaction. These are generally accepted methods of eliciting patient satisfaction, but tend to give high ratings. ${ }^{14} 16$ As shown in table I, $82 \%$ of the patients were to a large degree satisfied with their primary care encounter. The cut off point between satisfied and less satisfied, between 2 and 3 on the six point scale we used, was arbitrary. As 76\%-84\% levels of satisfaction have been found in most other studies, ${ }^{17}$ this seems to be a valid demarcation.

A major reason for the strong link between personal care and patient satisfaction may be found in an understanding of the psychosocial mechanisms underlying satisfaction. According to Pascoe, satisfaction consists of "health care recipients' reactions to salient aspects of the context, process and result of their experience." ${ }^{\prime 14}$ In the present setting satisfaction may be understood as the patient's reaction to the consultation and its outcome, relative to a conscious or subconscious standard that the patient had set before or during the encounter. This standard may be formed from a subjective ideal, a sense of what one deserves, or a minimal acceptable standard and is usually influenced by a subjective average of past experiences in similar situations. ${ }^{14}$ With continuity of care and accumulated knowledge about the specific physician and the consultation setting, the patient's standard may be set more realistically and major discrepancies between expectation and experience may be less common, thus increasing the likelihood of satisfaction. Furthermore, the personal connections that frequently develop in an ongoing patient-doctor relationship ${ }^{18}$ may increase patients' tolerance by widening the latitudes of acceptance around their subjective standard, thereby increasing the chance of satisfaction.

Continuity of care and satisfaction are bidirectionally related. In addition to continuity leading to increased satisfaction, satisfaction ratings predict what patients will do next time they need health services. ${ }^{19}$ In all primary health care systems, but most obviously in the open ones, incompatibility problems may cause the patients to use their "exit" option and change doctors. ${ }^{20}$ Some of the increase in satisfaction that takes place over time, as seen in table II, may be related to this. Unsatisfied patients who often change doctors have short patient-doctor relationships. After trial and error the patient may find a doctor fitting his or her own style and standard, causing the significant increase in satisfaction found with longitudinal care. It is of interest to note that the frequency of visits does not have the same effect.

In 1987 about a third of Norwegian general practitioners were salaried and worked in practices owned by the municipalities. The remaining two thirds owned their own practices and were reimbursed by the national health insurance on a fee for service basis. ${ }^{2 i}$ The general standard of care in the two types of practices was much the same, and for the individual patient these differences had no economic consequences. After each consultation, regardless of the doctor's reimbursement system, the patient paid a set fee directly to the doctor's office. Information about the reimbursement system was elicited from the doctor; most patients would not know which system their doctor was on. In spite of this patients had a $40 \%$ increased chance of being satisfied with consultations 
with doctors on a fee for service system as compared with those with salaried doctors. Thus not the monetary aspect as such, but rather something in the way the two different groups of doctors arrange or run their practices, seems to influence patient satisfaction. As has been found by other studies, ${ }^{14}$ the doctor's availability, here measured as the average hours of clinical practice a week, increased patient satisfaction with consultations. Inasmuch as patient satisfaction is important, part time partnerships and the ownership structure may be relevant factors to consider when planning primary health care systems.

Patients with psychosocial reasons for encounter showed significantly less satisfaction with their consultations than patients coming for other, usually somatic reasons. This may be due to the possibility that patients with psychosocial problems actually get inferior care. Psychosocial problems may be more time consuming, complex, and difficult for the physician to handle than somatic problems, or the patients may have unrealistic expectations of help. Another reason may be that these patients often are depressed or have unfavourable life circumstances. Studies suggest, however, that patients' assessments of service are relatively independent of depression and general life outlook, ${ }^{14}$ making this explanation less likely. This finding may furthermore be influenced by the new international classification of primary care system itself, recording the patient's major reason for consultation rather than the final diagnosis. When evaluating patient satisfaction, however, the reason for contact seems to be the most valid measure. With the patient-doctor relationship and continuity of care being integral parts of both diagnosis and treatment in patients with psychosocial problems, ${ }^{22}$ it seems important to further evaluate why these patients are less satisfied with their consultations.

The present study shows a link between personal, continuous care and patient satisfaction. If patient satisfaction is accepted as an integral part of quality health care, reinforcing personal care may be one way of increasing this quality.

1 Fitzpatrick R. Surveys of patient satisfaction. I. Important general considera tions. BMF 1991;302:887-9.

2 Roter D, Hall J, Katz N. Relations between physicians' behaviors and analogue patients' satisfaction, recall, and impressions. Med Care 1987;25: 437-51.

3 Fitzpatrick R, Hopkin A, Harvard-Watts O. Social dimensions of healing: a longitudinal study of outcomes of medical management of headaches. Soc Sci Med 1983;17:501-10.

4 Ware J, Snyder M. Dimensions of patient attitudes regarding doctors and medical services. Med Care 1975;13:669-79.

5 Freeman GK. Continuity of care in general practice: a review and a critique. Fam Pract 1984;1:245-52.

6 Banahan BF, Banahan BF III. Continuity as an attitudinal contract. 7 Fam Pract 1981;12:767-8.

7 Pendleton D, Schofield T, Tate P, Havelock P. The consultation: an approach to learning and teaching. Oxford: Oxford University Press, 1984

8 Hall JA, Dornan MC. What patients like about their medical care and how often they are asked: a meta-analysis of the satisfaction literature. Soc $S c i$ Med 1988;27:935-9.

9 Keeley D. Personal care or the polyclinic? BMf 1991;302:1514-6.

10 Hjortdahl P, Borchgrevink CF. Continuity of care: influence of general practitioners' knowledge about their patients on use of resources in consultations. BMF 1991;303:1181-4.

11 Lamberts $\mathrm{H}$, Wood $\mathrm{M}$, eds. ICPC: international classification of primary care. Oxford: Oxford University Press, 1987.

12 Hosmer DW, Lemeshow S. Applied logistic regression. New York: Wiley, 1989. 13 Rutle O. Pasienten fram i lyset-analyse av legekontaktar $i$ primerhelsetenesta [Getting the patient into the limelight: an analysis of encounters in primary [Getting the patient into the limelight: an analysis of encounters in primary
health care]. Oslo: Statens Institutt for Folkehelse, 1983. (Report

14 Pascoe GC. Patient satisfaction in primary health care: a literature review and analysis. Evaluation and Program Planning 1983;6:185-210.

15 Harris R. Improving patient satisfaction through action research. 7 Appl Behav Sci 1978;14:382-99.

16 Fitzpatrick R. Surveys of patient satisfaction. II. Designing a questionnaire and conducting a survey. BMF 1991;302:1129-32.

17 Hall JA, Dornan MC. Meta-analysis of satisfaction with medical care: description of research domain and analysis of overall satisfaction levels. Soc Sci Med 1988;27:637-44.

$18 \mathrm{McWhinney} \mathrm{IR.} \mathrm{A} \mathrm{textbook} \mathrm{of} \mathrm{family} \mathrm{medicine.} \mathrm{New} \mathrm{York:} \mathrm{Oxford} \mathrm{University}$ Press, 1989

19 Marquise MS, Davies AR, Ware JE. Patient satisfaction and change in medica care provider: a longitudinal study. Med Care 1983;21:821-9.

20 Hirschman AO. Exit, voice and loyalty: responses to decline in firms, organizations, and states. Cambridge, Massachusetts: Harvard University Press, 1970.

21 Hiortdahl P. General practice and continuity of care: organizational aspects. Fam Prac 1989;6:292-8.

22 Murphy M. Somatisation: embodying the problem. BMF 1989;298:1331-2.
University of Wales College of Medicine, Cardiff CF4 4XN Norman J Vetter, senior lecturer, department of epidemiology and community medicine

Peter A Lewis, senior lecturer, department of medical computing

Lise Llewellyn, lecturer, department of public health medicine

BMF 1992;304: 1290-2

\title{
Supporting elderly dependent people at home
}

\author{
Norman J Vetter, Peter A Lewis, Lise Llewellyn
}

Abstract

Objective-To clarify the relation between the dependency of elderly people and the assistance they receive from others by using a detailed but simple measure of dependency.

Design - Secondary analysis of data from a survey of people aged 70 and over.

Setting-Two general practices in south Wales.

Subjects -1280 people aged 70 and over.

Main outcome measures-Dependency on others to perform essential functions; detailed data on who assists with those functions.

Results-Increasing dependency was associated with increased use of more than one member of the family or friends and an increase in the provision of statutory services.

Conclusion-The complexity of the relation between dependency and those who care for dependent people has previously been underestimated. The presence of providers of statutory services at the household of elderly dependent people suggests that these services can be developed further to help those caring for elderly people at home.

\section{Introduction}

For many years it has been the policy of the Department of Health to maintain elderly people at home for as long as this remains a viable alternative. Most elderly people, when asked, agree with this and reinforce it by saying that, even if quite severely dependent on others, they would prefer to be managed at home. Further, they state that members of their family will be available to assist.

There are two aspects to the home care of elderly dependent people by their families: the degree of dependency of that person and the ability of the carer to cope in physical, mental, and social terms. Previous work has concentrated on the second aspect. This paper uses data from a previously published study ${ }^{2}$ to explore the interrelation between the dependency of elderly people and the contribution made to their care by relatives, friends, and the statutory services. This reanalysis has led us to revise the original findings of the survey.

We believe that survey groups and methods used previously on this topic have inadvertently led to an underemphasis on the contribution that service providers make to the home care of elderly dependent people. This has had important repercussions on the development of relevant services.

\section{Method}

This paper presents a reanalysis of data obtained from a study published previously, which was the first 